\title{
LOCALIZATION ECONOMIES IN THE THEME PARK INDUSTRY*
}

\author{
Bradley M. Braun and Ady Milman"*
}

\section{Introduction}

Central Florida boasts one of the largest concentrations of theme parks in the world. Disney World, the industry's dominant firm, has the two largest theme parks (EPCOT Center and Magic Kingdom), each drawing over $80 \%$ of all Central Florida tourists who visit at least one theme park (Florida Division of Tourism, 1987). However, within a 70 mile radius of the Disney theme parks, there are over 20 additional parks. Table 1 shows the percentage of tourists who visit each of the area's eight largest parks. The purpose of this paper is to test the hypothesis that unit savings costs that accrue to customers through the decrease in the real costs of time and travel is an important factor in explaining agglomeration of the industry.

\section{Contemporary Theme Park Development}

The theme park industry does not have a long history. Forerunners of the modern theme park include the British Crystal Palace, Coney Island, and the State Fair. Although one-day amusement parks still exist, the industry has evolved from parks designed for a one day family outing to parks characterized by fortnight length vacations in distant locations.

One distinguishing feature of theme parks is that most are open year round, allowing them to out-draw seasonal attractions and parks. To provide a suitable climate for year-round operation, most theme parks are located in sun-belt areas. It is no surprise that four of the most popular theme parks in the United States are located in Central Florida. ${ }^{1}$

The growth in the theme park industry can be traced to changing vacation preferences and increasing disposable incomes, which have led to more frequent travel to more distant locations. Additionally, declining air travel costs and the expanding interstate highway system have permitted economies of scale to be reached in centrally located theme parks.

\footnotetext{
- The Authors wish to thank the anonymous reviewers for their many useful comments.

- Assistant Professor of Economics, and Assistant Professor of Hospitality Management, University of Central Florida.
}

The Central Florida Theme Park Industry

The Central Florida theme park industry is dominated by Walt Disney World (WDW), which has grown over the past two decades to include three theme parks, a movie studio, a night entertainment complex, two water parks, and eleven hotels. Disney has announced a one billion dollar expansion plan that will add seven hotels, a fourth theme park, and 29 attractions for its three existing parks over the next ten years.

The continued concentration of Disney's Florida operations is a classic case of agglomeration economies based on declining unit costs as the scale of operations increases. The very large fixed costs resulting from Disney's large investment in land and capital make large scale utilization desirable to spread the fixed costs over many units (Isard, 1972). At the same time, non-Disney attractions and hotels continue to be built within an eight mile radius of Disney. ${ }^{2}$

The clustering of competing parks and the expansion of pre-Disney attractions in Central Florida implies that a second type of agglomeration economies, localization economies, are at work as well. Localization economies are associated with the unit cost savings which arise when an industry agglomerates in a single location. While localization economies are often explained in terms of each firm's savings on unit production costs, it has also been recognized that they can occur in the sale of output. The unit savings costs in the sale of output accrue to customers through the decrease in the real costs of time and travel (Heilbrun, 1987).

If localization economies exist in the sale of output, they reduce consumers' unit costs; consequently, the demand relationship of each smaller park to Disney should be sensitive to its distance from Disney, ceteris paribus. This is the hypothesis that is tested. It is also expected that other park attributes will influence the demand relationship. Finally, this analysis cannot rule out localization economies in production.

\section{Theme Park Consumption}

The theme park industry provides a non-durable consumer product within the service sector and recreational and tourism services sub-sector. Tourists who visit 
Table 1

Distribution of Central Florida Theme Park Attendance

\begin{tabular}{lc}
\hline Theme Park & Attendance \\
\hline Magic Kingdom & $84.2 \%$ \\
Epcot & $83.0 \%$ \\
SeaWorld/Orlando & $57.1 \%$ \\
Busch Gardens/Tampa & $21.1 \%$ \\
Kennedy Space Center & $21.1 \%$ \\
Cypress Gardens & $19.8 \%$ \\
Wet N' Wild & $12.1 \%$ \\
Silver Springs & $2.0 \%$ \\
\hline
\end{tabular}

Source: Dick Pope Sr. Institute for Tourism Studies, University of Central Florida.

Central Florida and its theme parks consume a composite good called a vacation. Households assess the relative merits or attributes of each alternative vacation package. In terms of vacation costs, travel and accommodation most often dominate, while the cost of leisure activities is a relatively smaller component (Bechdolt, 1973). Also, once a vacation destination that includes theme parks is chosen, the consumer faces a reduced set of recreation choices. For these reasons, it is not surprising that the demand for theme parks has been found to be price inelastic (See Mathieson and Wall, 1982). However, no research has explored the demand relationships among competing theme parks.

There exists a feeling among many local economists and tourism experts that Disney provides a unique experience with no substitutes because of its size and scope. They feel that because most tourists visit a number of competing theme parks during their stay, there is a complementary relationship among parks. Intuitively, once vacation plans have been made and the relatively high transportation costs of getting to Florida have become sunk costs, the household consumes the various attractions together. If this intuition is correct and the hypothesis concerning localization economies is true, then demand analysis should reveal a complementary relationship of the smaller theme parks with Disney that weakens as the distance attribute increases, ceteris paribus. However, it is not the relationship but the relative strength with respect to distance that is used to test the localization hypothesis.

\section{Methodology}

\section{Data Source and Description}

To test the hypothesis, the demand analysis used a proxy for theme park attendance based on survey data collected by the Florida Division of Tourism (1987), Office of Marketing Research. The survey compiles quarterly visitor profile information using personal interviews with questions on household and trip characteristics of the travelling party, including which theme parks were visited. These interviews are conducted year-round with Florida's visitors who remain in the state for at least 24 hours. Interviews with auto visitors are conducted on the main entry points into Florida (i.e. I-10, US-231, I-75, I-95, and US-1). Interviews with air visitors take place in the departure lounges of nonstop commercial flightsat Florida's major airports (i.e. Miami, Ft. Lauderdale, West Palm Beach, Orlando, Tampa, Jacksonville, Sarasota, and Ft. Myers). The number of surveys administered at each interview site is proportionally allocated by the traffic volume of each road or airport.

To insure that the sample allowed for interaction among the competing parks, two criteria were used to determine whether a survey participant was also part of the attendance proxy. The first was the major destination of the travel party. Only those households whose major destination was the Orlando MSA were included. The second criterion was that a household must have visited at least one theme park in Central Florida during their stay. The aggregate data was thus transformed to yield the proportion of the Orlando MSA's air and auto visitors who attended theme parks during each of the four quarters covering the years 1985-1987.

In general, auto visitors whose major destination was the Orlando MSA and who visited at least one theme park were found to have remained in the area for seven and a half days. For air visitors with a similar profile, the time spent in the area was five and three quarter days. ${ }^{3}$ These proportions were multiplied by the estimated total number of visitors to Florida to provide a proxy for theme park attendance. 
Entrance prices were obtained from The Orlando Sentinel and directly from the parks. These prices were collected at the beginning and end of each month to calculate a quarterly mean price for each park. Quarterly prices were used because theme park prices exhibit no short run variation. There are two reasons for the lack of short run price variation. First, the theme park industry has not used price competition or discounting to increase attendance. ${ }^{4}$ Instead, the industry has relied on non-pricing strategies such as give-aways of cars and cash, the construction of new attractions within existing theme parks, and the building of new theme parks. As shown by Fritz (1990), these strategies encourage repeat visits and stimulate substitution away from other types of vacations.

The second reason for the lack of price variation is that theme parks charge a single price and, unlike other industries, place no explicit constraints on the quantities that each person can consume. Rationing is governed by each visitor's time value. During peak attendance periods, park capacity imposes an explicit constraint on the quantity consumed. Therefore, the length of the queue acts to increase or decrease the effective price per ride. In the short term, effective prices vary with demand while actual entrance prices at the theme parks remain unchanged (Barro, 1986).

\section{The Model}

With 16 observations per theme park, the demand analysis used a covariance model on the pooled crosssection and time series data. ${ }^{5}$ In the covariance model, dummy variables were used to determine changes in the default slope and intercept. The dependent variable of the model was the pooled attendance figures of the six largest parks, other than Disney, shown in Table 1. The independent variables included the real admission prices of the six parks, the real mean admission price of Disney ${ }^{6}$, and the total number of tourists to the area. ${ }^{7}$ The total number of visitors to the Orlando MSA was included to filter out the seasonal fluctuation in attendance. The model is written as:

$$
A_{i j}=B_{0}+B_{1} P_{d j}+\sum B_{k}\left(P_{d j} D_{k}\right)+B_{7} P_{i j}+B_{8} T_{j}+\varepsilon
$$

where $A_{i j}=$ attendance at park $i$, in period $j$

$\mathrm{P}_{\mathrm{dj}}=$ real mean price of Disney, in period $\mathrm{j}$

$B_{k}=$ incremental change in $B_{1}$

$D_{k}=$ dummy variable $=1$ if attraction $k, 0$ otherwise

$P_{i j}=$ real price of park $i$, in period $j$

$\mathrm{T}_{\mathrm{j}}=$ total area tourists, in period $\mathrm{j}$

$\mathrm{j}=1,2,3, \ldots, 16 \mathrm{jth}$ observation

$i=1,2, \ldots, 6$ ith park ${ }^{*}$

$$
k=2,3, \ldots, 6 \text { kth park }{ }^{*}
$$

*For i and k, 1 = SeaWorld, 2 = Busch Gardens, 3 = Kennedy Space Center, 4 = Cypress Gardens, $5=$ Wet $\mathbf{N}^{\prime}$ Wild, $6=$ Silver Springs

The demand relationship of each of the six theme parks with Disney can be determined by estimating the cross price elasticities of demand. As shown by $\mathrm{Hu}$ (1982), the cross price elasticity of attraction $i$ with respect to Disney, denoted as $\mathrm{E}_{\mathrm{di}}$, is calculated as: ${ }^{8}$

\section{$E_{d 1}=\left(\partial A_{1} / \partial P_{d}\right)\left(P_{d} / A_{1}\right)=B_{1}\left(P_{d} / A_{1}\right)$}

$=$ cross price elasticity of the default park (SeaWorld).

$E_{d k}=\left(B_{1}+B_{k}\right)\left(P_{d} / A_{k}\right)=$ cross price elasticity of the kth attraction where $A$ and $P$ denote the mean attendance and price of each attraction, and $\left(B_{1}+B_{k}\right)=$ adjusted slope.

A cross price elasticity of demand less (greater) than zero indicates a complementary (substitute) relationship between Disney and the park in question. In the sale of output, it is not the type of relationship that is critical for the localization economies hypothesis, but the relative strength of those relationships.

\section{Regression Results}

The regression estimates, as reported in Table 2 , show that both auto and air tourists view competing theme parks in the same manner. However, two important differences exist between auto and air tourists. First, the seasonal adjustment parameter, $B_{8}$, is only significant for auto tourists. This indicates that the seasonal fluctuation in air tourism is weak. Second, the slope parameter is significant only for auto tourists. This would indicate that air tourists are not as sensitive to the prices of the theme parks. Some reasons for this include their relatively higher transportation costs, their higher household incomes, and their smaller travel party size. On the other hand, both auto and air tourists appear to be sensitive to the relative prices of competing parks.

From the estimated regression parameters, the cross price elasticities were calculated(Table 3 ). These estimated elasticities indicate that both auto and air tourists do not view the alternative theme parks as complements, but rather as substitutes for Disney. As the attribute of distance from Disney increases, the relationship weakens. Air tourists appear to be much more sensitive to distance than do auto tourists. This result suggests that with a shorter length of visit, the decrease in the real cost of time and travel is larger for air tourists. However, a number of additional factors such as the size and age distribution of 
Table 2

Summary of Regression Coefficients

\begin{tabular}{|c|c|c|c|c|c|}
\hline \multirow{2}{*}{$\frac{\text { Coefficient }}{B_{0}}$} & \multirow{2}{*}{$\begin{array}{l}\text { Variable } \\
\text { Intercept }\end{array}$} & \multicolumn{2}{|c|}{ Auto } & \multicolumn{2}{|c|}{ Air } \\
\hline & & 10.08 & $(0.79)$ & 5.14 & $(0.81)$ \\
\hline$B_{1}$ & $P_{d i}$ & 2.66 & $(2.56)^{*}$ & 1.94 & $(2.96)^{*}$ \\
\hline$B_{2}$ & $P_{\mathrm{dj}} D_{2}$ & 0.68 & $(4.53)^{*}$ & 0.44 & $(-4.31)^{*}$ \\
\hline$B_{3}$ & $\mathrm{P}_{\mathrm{dj}} \mathrm{D}_{3}$ & -0.81 & $(-3.23)^{*}$ & 1.42 & $(-2.13)^{*}$ \\
\hline$B_{4}$ & $\mathrm{P}_{\mathbf{d j}} \mathrm{D}_{4}$ & -1.57 & $(-3.84)^{*}$ & 1.44 & $(-7.37)^{*}$ \\
\hline$B_{5}$ & $\mathrm{P}_{\mathrm{dj}} \mathrm{D}_{5}$ & -1.87 & $(-2.08)^{*}$ & 1.63 & $(-5.87)$ \\
\hline$B_{6}$ & $P_{d_{j i}} D_{6}$ & -2.01 & $(-5.73)^{*}$ & 1.77 & $(-5.58)^{*}$ \\
\hline$B_{7}$ & $\mathbf{P}_{\mathrm{ij}}$ & -3.63 & $(-2.09)^{*}$ & 0.58 & $(-0.53)$ \\
\hline \multirow{3}{*}{\multicolumn{2}{|c|}{$\begin{array}{c}\mathbf{r}^{2} \\
\text { F-Stat }\end{array}$}} & 5.14 & $(3.81)^{*}$ & 0.17 & $(0.25)$ \\
\hline & & 0.73 & & 0.88 & \\
\hline & & $29.97^{*}$ & & $65.83^{*}$ & \\
\hline
\end{tabular}

* indicates significance at the $95 \%$ level. T-statistics in parenthesis.

travel parties, household income, and other park attributes also influence the strength of the demand relationship.

The substitute relationship is strongest for those parks that have more attributes and, therefore, provide a "tourist experience" more similar to Disney's. These attributes include a variety of shows, restaurants, landscaping, architecture and so on. For example, even though Busch Gardens is farther from Disney than Cypress Gardens, both have similar cross price elasticities for auto tourists. That is, the larger number of attributes at Busch Gardens makes visitors more willing to travel the extra distance. However, air tourists view the less distant park with fewer attributes as the better substitute for Disney.

\section{Conclusion}

Contrary to popular opinion, the preceding demand analysis has shown a substitute relationship among theme parks in Central Florida. The analysis also showed that the degree of substitutability of a park with respect to Disney increases with both distance from Disney and the number of attributes.

These findings can be explained by two primary reasons. First, over seventy-eight percent (seventy-two percent) of auto (air) tourists who travel to Central Florida and attend at least one theme park are repeat visitors. Consequently, they are more price sensitive. As a result,

Table 3

Estimated Cross Price Elasticities of Demand

\begin{tabular}{lcccc}
\hline \multicolumn{1}{c}{ Park } & Auto & Air & $\begin{array}{c}\text { Distance } \\
\text { From Disney } \\
\text { (In Miles) }\end{array}$ & $\begin{array}{c}\text { Attribute } \\
\text { Index }\end{array}$ \\
\hline SeaWorld & 1.39 & 1.40 & 4 & 4.68 \\
Busch Gardens & 0.29 & 0.19 & 64 & 3.51 \\
Kennedy Space Center & 0.11 & 0.12 & 68 & 1.10 \\
Cypress Gardens & 0.29 & 0.21 & 28 & 2.77 \\
Wet N' Wild & 0.09 & 0.19 & 13 & 0.65 \\
Silver Springs & 0.27 & 0.20 & 97 & 2.57 \\
\hline \hline
\end{tabular}


once Disney has been visited, the smaller attractions can offer a few hours experience at a much lower admission price.

The second reason is that almost all theme parks offer similar leisure experiences. Individuals feel obliged to visit a particular park because of other interested people in their party (children, spouse, friends), or because of "unconditional leisure activity" when they visit a park for their own intrinsic satisfaction (Milman, 1988). Since the experience is similar in all theme parks, households are more likely to choose a larger park to insure that there are activities of interest to each member of the travel party.

These results support the hypothesis that localization economies exist to lower the real time and travel costs to consumers. Also, industry development and expansion over the past few years seems to support the conclusion. New Central Florida parks, such as Universal Studios, are located within the same eight mile radius from Disney. At the same time, however, localization economies in production cannotbe ruled out. For example, Central Florida's theme parks have access to a large pool of experienced entertainers, and Disney's national advertising generates external benefits by increasing the pool of visitors. Both of these factors would tend to lower unit costs within the industry.

The conclusions of this paper would indicate that new entrants into areas of highly concentrated theme parks will be more successful if their distance from the dominate firm is small, and their number of attributes is large.

\section{Notes}

'Themost popular in 1988 were WDW's Magic Kingdom and EPCOT, with combined attendance of 26 million visitors; the third most popular was SeaWorld of Orlando with 4.1 million and the fifth was Busch Gardens with 3.4 million.

${ }^{2}$ Located 6 miles from Disney, Universal Studios will open in the spring of 1990. Stauffer-Powers Inc. has announced the construction of a themed attraction within 3 miles of Disney. Also, over 99 percent of thenation's largest concentration of hotel space is located within 6 miles of Disney.

${ }^{3}$ Although a large number of air tourists rent automobiles upon arrival, the demographic distinctions between the auto and air visitors remains unchanged. In addition to shorter length of stay, the major differences of air from auto travelers are smaller party size and larger household income.

"Price discounting does take place in the form of price discrimination during off-peak months for Florida residents.

sThe specific version of the final covariance model estimated in this paper is called the least squares dummy variables (LSDV) model, indicating the appropriateness of the least squares estima- tion method (See Kmenta, 1986, pp. 630-635).

Themean price of Disney was calculated from single day and multi-day prices.

TPersonal income and dummy variables to adjust for differences in the intercept were initially included but were not found to be significant.

Soe Hu (1982), pp. 67-69.

The attribute index was constructed from a survey of Central Florida's theme park visitors which asked respondents to reveal preference for various theme park attributes (Milman, Spring 1988). The percentage responses of the most popular attractions included Man-made Attractions of Fantasy and Technology (75.1\%), Animal Shows (61.8\%), Botanical Gardens (59.5\%), Exotic Animal Exhibits (57.5\%) and Educational Exhibits (49.8\%). To calculate a park's index, the percentage responses for each of the park's attributes were summed. For example, if a park only had Botanical Gardens and an Exotic Animal Exhibits, its attribute index would be 1.17 .

\section{References}

Barro, Robert. "Ski-Lift Pricing." American Economic Review. 77 (December, 1987). 875-90.

Bechdolt, B.V. "Cross-Sectional Travel Demand Functions- U.S. Visits to Hawaii 1961-1970." Quarterly Review of Economics and Business. 13 (Winter, 1973). 37-47.

Florida Department of Commerce. Air and Auto Survey. Tallahassee, FL.: Florida Department of Commerce, Division of Tourism, 1985-87.

Fritz, Richard C. "Strategic Planning With Systems Dynamics Model For Regional Tourism Site Development." The Review of Regional Studies. 19(1) (Winter, 1990). 57-71.

Heilbrun, James. Urban Economics and Public Policy, 3rd Edition. New York, NY.: St. Martin's Press, 1987.

Hu, Teh-wei. Econometrics. Baltimore, MD.: University Park Press, 1982.

Isard, Walter. Location and Space-Economy. Cambridge, MA.: M.I.T. Press, 1972.

Kelly, John R. Leisure. Englewood, NJ.: Prentice Hall, 1982.

Kmenta, Jan. Elements of Econometrics, 2nd Edition. New York, NY.: Macmillan Publishing Co., 1986.

Lyon, Richard. "Theme Parks in the USA." Travel and Tourism Analyst. The Economist Publications Limited, January, 1987.

Mathieson, Allister, and Geoffrey Wall. Tourism: Economic. Physical, and Social Impacts. New York, NY.: Longham, 1982.

Milman, Ady. "Market Identification of a New Theme Park: An Example from Central Florida." Journal of Travel Research. 26(4) (Spring, 1988). 37-50. 